\title{
MICROSTRUCTURE EVOLUTION IN LASER-DRESSING OF ALUMINA GRINDING WHEELS
}

\author{
Abhijeet Khangar, Narendra B. Dahotre, S. Nayak
}

Department of Materials Science \& Engineering, 10521 Center for Laser Applications, Univ. of Tennessee, Knoxville-37932

Grinding is a manufacturing process to achieve the desired surface finish on component. Due to continuous grinding operations, the grinding efficiency deteriorates as the sharp (cutting) edges become blunt $[1,2]$. Dressing is a sharpening operation designed to generate a surface topography on the cutting face of the wheel, hence restoring grinding efficiency. High power laser is being explored as a non-contact type dressing technique [3]. A $2.5 \mathrm{~kW}$ Hobart continuous wave Nd:YAG laser was used for dressing $\mathrm{Al}_{2} \mathrm{O}_{3}$ grinding wheel and various laser powers were employed to dress the entire surface by scanning the laser beam in parallel tracks at a speed of $50 \mathrm{~cm} / \mathrm{min}$. Within the range of laser power employed, sample surface underwent a transformation ranging from solid-solid to liquid-solid, thus forming a uniform resolidified layer on the surface for the higher laser powers.

Coating the sample with conducting material for Scanning Electron Microscopy (SEM) work would introduce artifacts. Hence, to avoid charging, variable pressure ( $\sim 30 \mathrm{~Pa}$ air $)$ was maintained in the SEM chamber. The microstructural analysis of the dressed wheel surface showed grain refinement (FIG 1a and 1b). Micro cutting edges are produced on the individual grains. Though a wide distribution on size of the grains was seen, the shape was more regular (equiaxed) with well-defined vertices and edges on each grain (FIG 2). This faceted structure on the particles with well-defined vertices and edges can provide cutting edges for improved grinding. Also, the porosity in the region near the surface was reduced and dendritic growth was observed on individual particles (FIG 3). In the region between the particles, the shape of the grains was cubic (FIG 4) and the interlocking between these cubic grains seemed to be the reason for bonding between the individual particles. Area analysis by Energy Dispersive Area X-ray Analysis (EDAX) revealed the presence of Al, Cr, $\mathrm{O}, \mathrm{Si}, \mathrm{K}$ and $\mathrm{Na}$. However, X-ray diffraction carried on the samples indicated presence of only $\mathrm{Al}_{2} \mathrm{O}_{3}$ phases. Hence $\mathrm{Cr}, \mathrm{Si}, \mathrm{K}, \mathrm{P}$ and $\mathrm{Na}$ were present either in solid solution with $\mathrm{Al}_{2} \mathrm{O}_{3}$ or in a glassy phase, and hence not detected by X-ray diffraction. The upper resolidified layer was containing $\mathrm{Si}, \mathrm{Na}, \mathrm{K}$ and $\mathrm{P}$ where as the material beneath it was primarily $\mathrm{Al}, \mathrm{Cr}$ and $\mathrm{O}$. This observation in conjunction with microstructural studies suggests that a glass phase (with Al, O, Na, $\mathrm{K}, \mathrm{P}$ and $\mathrm{Si}$ ) is formed on the surface in the near-ridge regions. Breakage of this glass layer would expose new cutting grains with edges and vertex. Modification in the structure in laser treatment of the surface of the alumina grinding wheel appears to have great potential.

\section{References:}

[1] N. Ramesh Babu et al, J of Engg. For Industry, Vol.111, Aug 1989, pp 244-252.

[2] Mark J. Jackson et al, J. of Materials Processing Technology, 2000, 108, pp 114-124.

[3] C. Zhang et al, Int. J of Machine Tools \& Manufacture, January 2002, 42, pp 825-835.

[4] The authors appreciate Dr. Mark J. Jackson for providing grinding wheel samples for the research work. 


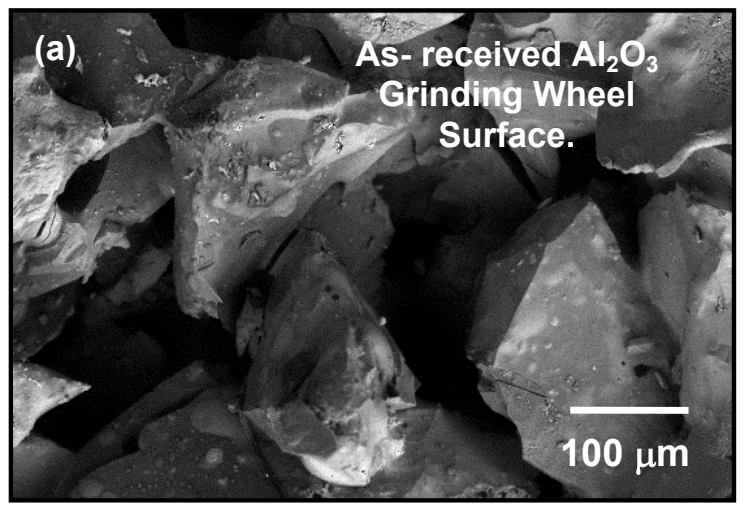

FIG 1a: As-received $\mathrm{Al}_{2} \mathrm{O}_{3}$ grinding wheel surface characterized by large pores and limited bonding among the grains.

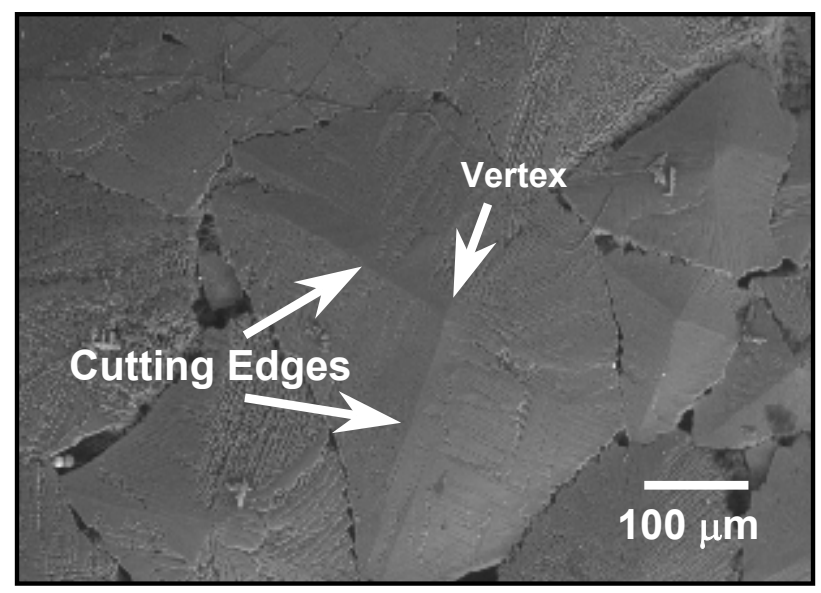

FIG 2: Cutting edges and vertex on individual particle with multi-faceted surfaces. Orientation of dendrites is different on each face.

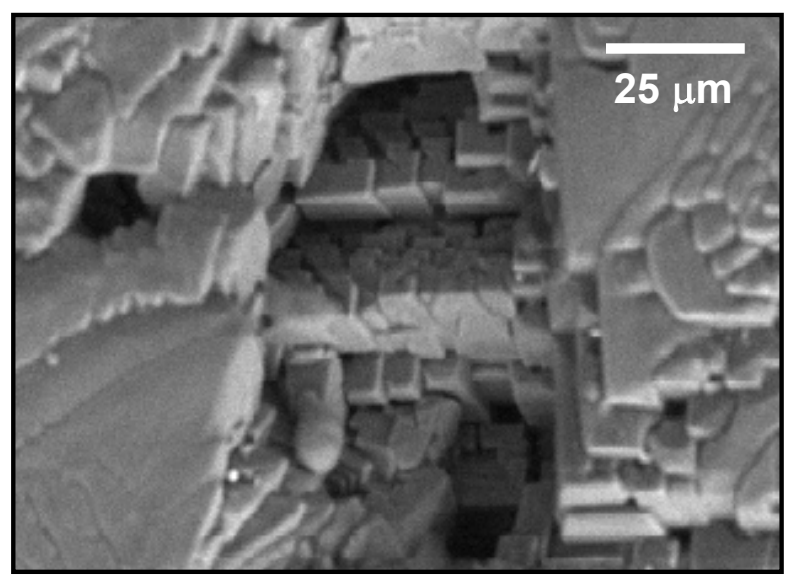

FIG 4: Interlocking/bonding between adjacent particles because of step-like grains formed in between them during laser dressing.

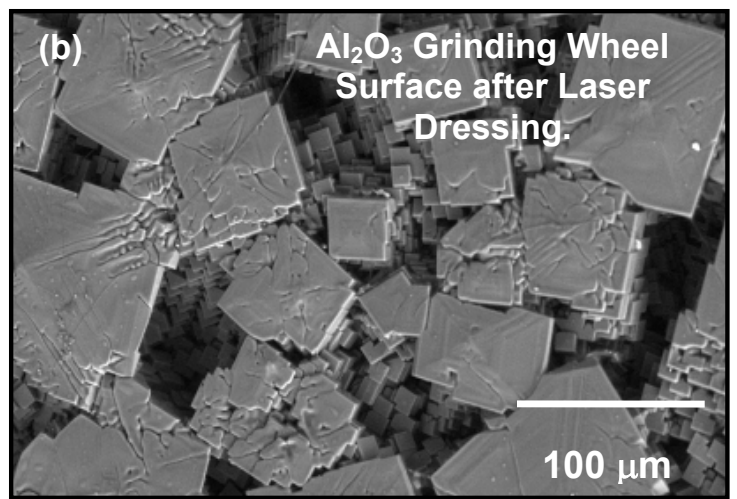

FIG 1b: Laser dressing caused densification, and refinement of the grain size on the wheel surface.

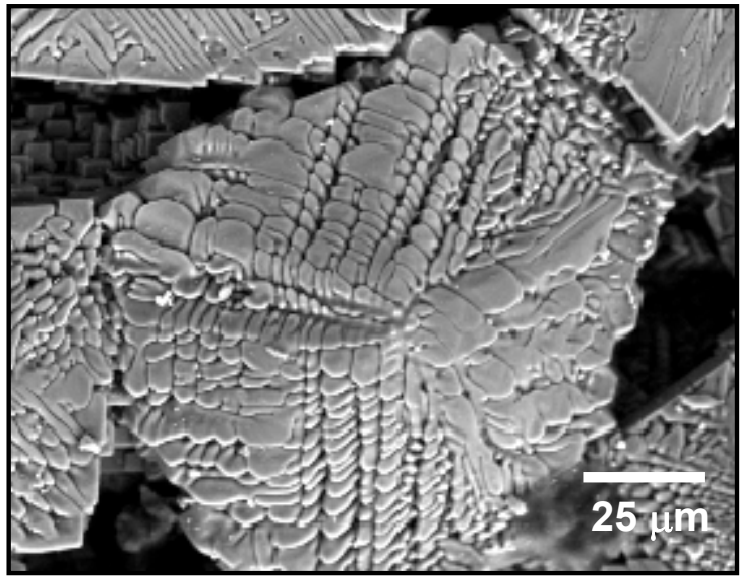

FIG 3: Individual particle on the laser dressed grinding wheel surface. Dendritic growth can be observed in different directions on the faces.

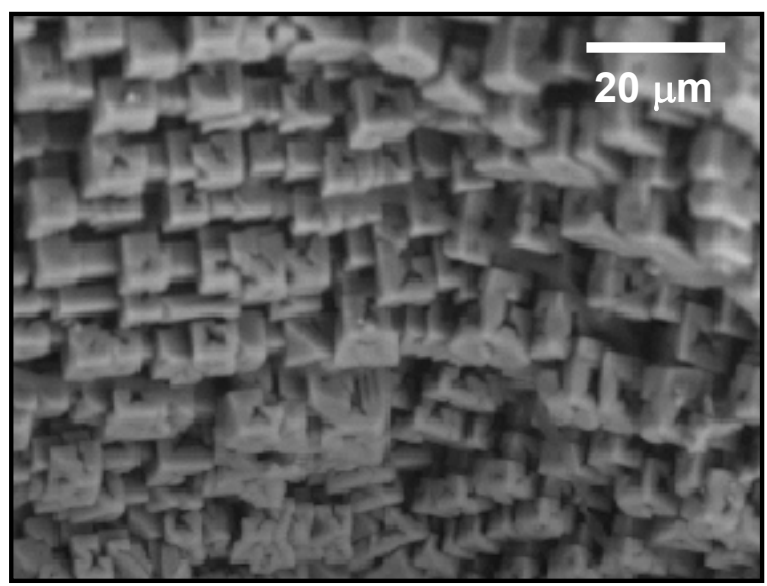

FIG 5: Some part of the resolidified layer on the surface has refined $\mathrm{C}$-shaped grains. 